\title{
PASCAL AND THE VOICELESSNESS OF DESPAIR
}

\author{
ALEXANDER JECH \\ University of Notre Dame
}

85. Good sense. They are forced to say: 'You are not acting in good faith, we are not asleep.' etc. How I love to see this proud reason humbled and begging! Those are not the words of a man whose rights are disputed and who is defending them strongly, arms in hand. He does not waste time saying that his opponents are not acting in good faith, but punishes their bad faith by force.

Blaise Pascal, Pensées

\section{THE DUAL PURPOSES OF MEANING IN LIFE}

Thaddeus Metz's Meaning in Life is like a magnificent castle, covering vast ground, with towers high into the heavens, and astoundingly intricate architecture. It covers the literature on meaning with enviable completeness and weaves together the many and various strands within that literature, 'towering' over the debates and issues and provides a wide and inclusive perspective on them. Meaning in Life is a striking achievement and, just as the intricacy of those fortresses testified to the growing maturity of architecture, so Metz's book is a testament to the growing maturity of the literature on the meaning of life.

But such castles had a dual purpose, which did not always cohere. They were fortresses intended to withstand armed assault, yet they were also supposed to manifest and project the aristocratic loftiness, status, and elegance of their masters. These purposes conflicted, especially in the design of a castle's central tower, the keep or donjon, where elegant ornamentation was most necessary, but which could hamper or compromise its defensive functions. Meaning in Life likewise seeks to fulfil a dual purpose: on the one hand, to weave all the literature together 
into a coherent conception of meaning, including supernaturalist conceptions of meaning; and, on the other, to neutralize supernaturalist claims that only the existence of God or of an immortal soul could provide the necessary conditions for meaning.

Does Metz's synthesis stand, or has it compromised its defence? Part II, 'Supernaturalist Theories of Meaning in Life', devotes four substantial chapters to exploring, articulating, critiquing, and reconstructing supernaturalist theories of meaning in life. Part II frequently adopts the methodology of Part I and III, which we can find epitomized in 8.4, page 144. Here, Metz writes that he finds the views of supernaturalist sceptics, who doubt that life can be meaningful if God or the soul does not exist, to be extremely 'counterintuitive', and predicts that regardless of how this turns out, 'many will respond' that they continue to find lives like those lived by Einstein, Darwin, Dostoyevsky, Picasso, Mandela, and Mother Teresa' to be meaningful.

Similar remarks go for actions that confer some meaning on a life, such as rearing children with love, patience, and insight, caring for students, parents, or hospital patients, having deep and long-lasting friendships, sustaining a vibrant and close marriage, engaging in charity work, creating artworks, making intellectual discoveries. These, too, appear capable of making a person's existence somewhat more significant in the absence of a perfect or supernatural condition. If so, then the best theoretical explanation of what confers meaning on a life cannot include the claim that a life would be utterly meaningless in the absence of the spiritual realm. ${ }^{1}$

The argument proceeds in two steps: it first collects a set of intuitive judgments, or judgments that most people would be inclined to agree with, and then it infers the theory that would correspond with these judgments.

But this method is a poor weapon to wield in a debate with the sceptics. It is in fact the first thing that must be safeguarded against attack. This problem may be made clearer if we examine a paradigmatic figure who represents the view that God is necessary for life to have meaning - one of those authors for whom the yearning for meaning appears in the midst of a cry of despair. I will focus upon Pascal, whose own method and conclusions sharply contrast with those displayed within Meaning in Life. I will first examine his conception of the human condition, then

${ }^{1}$ Thaddeus Metz, Meaning in Life (Oxford: Oxford University Press, 2013), p. 144. 
his explanation for how this condition gives rise to despair and the sense of meaninglessness, and finally how he thinks that the existence of God could restore meaning's possibility. I will then close with some concluding remarks on why a Pascalian sort of supernaturalist would not be satisfied with the arguments made in Meaning in Life and would, perhaps, regard them as so many additional evidences to the contrary.

\section{PASCAL ON THE HUMAN CONDITION}

Pascal is a difficult author. For all the clarity and logical rigor we find in his published papers, the reader of the Pensées encounters an unfinished work of cobbled-together fragments. Its pages shine with brilliant observations but it sprawls out with no obvious order, in apparently disorganized and contradictory array. In this, the work manifests the same apparent disorder it declares the world to possess, and this is an important part of its power. Making sense of his arguments requires patience, care, and constant attention.

Pascal is an anti-systematic thinker. He distrusts the vanity involved in system-building, which serves the pride of the philosopher, especially when this touches upon human nature (fr. 175). ${ }^{2}$ We possess 'two different natures' (fr. 144), both 'instinct' and 'reason', 'passion' and 'thought', 'greatness' and 'baseness', the 'angel' and the 'brute', combined in a confused mixture we cannot comprehend (frs. 164, 230). It is dangerous to understand only one of these: we must understand both our 'greatness' and our 'baseness' to think and live as we ought (frs. 153, 513). Yet, as if in procrustean competition, philosophers for the most part have tried to reduce human beings into one of these alternatives: 'Some wanted to renounce the passions and become gods, the others wanted to renounce reason and become brute beasts. But neither group succeeded' (fr. 29). ${ }^{3}$ From the Platonists, Stoics, and Epicureans of antiquity down to Descartes and Hobbes in Pascal's own time, philosophers were guilty again and again of oversimplifying the mixture that is humanity to one

${ }^{2}$ References to the Pensées are to Blaise Pascal, Pensées and Other Writings, trans. Honor Levi (Oxford: Oxford University Press, 1995), with the fragment number cited in text.

${ }^{3}$ Cf. Hubert Dreyfus, "What a monster then is man": Pascal and Kierkegaard on being a contradictory self and what to do about it', in The Cambridge Companion to Existentialism, ed. by Steven Crowell (Cambridge: Cambridge University Press), pp. 96-110. 
side or another of the mixture in order to render it more theoretically tidy and unified.

Pascal refuses either simplification; human nature contains both 'baseness' and 'greatness', and we are thoroughly contradictory (fr. 230). He also denies that we can, or should, aim to become wholly one aspect or the other. We can never escape the needs or properties associated with the half we try to suppress, and the attempt to do so only corrupts the aspect we pursue. Speaking of those who would attempt to live a purely spiritual existence, he says, 'Man is neither angel nor brute, and the unfortunate thing is that he who would act the angel acts the brute' (fr. 358). Human happiness requires that both sides of our nature be fulfilled, and not just one of these or the other. We fail at achieving happiness when either the brute's or the angel's desires are denied (frs. 110, 166) or when the war between these two aspects prevents us from finding any repose (frs. 29, 168).

Not only are we divided between our two aspects, however, we are also incapable of fulfilling the desires of either side of our nature. The rational aspect of our nature desires to know the truth but is trapped between ignorance and knowledge (fr. 230). We cannot help wanting to know the truth about human existence, but its accomplishment is impossible (fr. 110). Human reason is calculative, moving from premises to conclusions, and perfect in itself when its method is sound, ${ }^{4}$ but incapable of securing its first premises, which it acquires from 'nature. ${ }^{5}$ What we regard as nature, however, is subject to custom (fr. 164) and to the 'uncertain balance between truth and pleasure [...] in the deepest interior of a human being, ${ }^{6}$ in such a way and to such a degree that a person can rarely discern the difference between these, and frequently misleads us. The attempt to use our finite intellect in order to comprehend an infinitely great and infinitely divisible universe disorients our reason, which requires a resting point (fr. 230). For Pascal, human science necessarily includes a 'void' within it, 'at its foundation.7 Moral knowledge is incomparably more important to us than scientific knowledge (fr. 57), but the difficulty, or impossibility, of knowing ourselves or our true nature makes it even

${ }^{4}$ Pascal, 'The Art of Persuasion', in Pensées and Other Writings, pp. 196-197.

5 'The Art of Persuasion', p. 194.

6 'The Art of Persuasion', p. 195.

7 Jean Khalfa, 'Pascal's Theory of Knowledge', in Cambridge Companion to Pascal, ed. by Nicholas Hammond (Cambridge: Cambridge University Press, 2003), pp. 122-143 (p. 133). 
more elusive (fr. 230, 576). We are unsure even of how far our ignorance goes, because neither scepticism nor dogmatism can be established (fr. 164). The lack of a fixed point leaves us with the realization that for all reason can show us, every aspect of human life is contingent and accidental. The kind of cosmic order that the philosophers have sought, which would give us a clear sense of human identity and purpose, cannot be discerned; the universe is 'silent' (fr. 229).

The interaction of the rational and animal aspects of humanity is disordered. The desires rooted in the two aspects of our nature conflict with each other (fr. 514). They draw us in different directions and require different things of us; the difficulty of reconciling them is what has led philosophers to their inaccurate simplifications of human nature (fr. 29). Their combination produces the imagination, which fights against reason and renders the desires of the brute fantastical, unlimited, and incapable of satisfaction (fr. 78). Furthermore, reason reveals to the 'brute' that it must die. Death undermines contentment, for it is the most inescapable of our ills and our knowledge of its inevitable but unpredictable arrival is itself an enormous evil (fr. 681). Knowledge of death is so miserable that we require constant diversion or distraction to escape from its misery (fr. 166). The two aspects of ourselves do not fit together well; taken as a whole, man is a monstrous, incomprehensible being (fr. 163, 164).

Can the being nature left in painful perplexity overcome its condition by its own efforts at reform and enlightenment? Pascal's answer is a firm No: the causes of human misery escape human control. Our misery is matched by our weakness. The nature of our ignorance is itself a cause of our remaining in ignorance; our ignorance is not simple, so that our ignorance of a moral standard itself prevents us from identifying the moral standard. 'We need a rule' to determine which starting point to begin from, but 'reason is pliable in either direction', and so 'there is no rule' (fr. 455). We have no power to overcome human mortality. And no one has yet found a means of making the passions and reason live with each other; nor is it clear how someone could. The wretchedness of the human condition, combined with our powerlessness to make it anything else, lies at the root of the great restlessness that marks human nature. When happiness is impossible, our happiness is best served if we avoid dwelling upon its impossibility, because doing so would make us even worse off and more miserable than before: 'men have decided for their own happiness not to think about it' (fr. 166). The only remedy available requires turning to God for help, which is contrary to our passions. 
Therefore, we 'doggedly refuse to face our misery' ${ }^{8}$ and seek distractions instead.

\section{THE DESTRUCTION OF MEANING}

Pascal, we sense, is not an optimist about the human condition. How does this inform his sense of the meaningfulness of human life? Because he is not concerned with the question of meaning as such, it requires some work on our part to draw out the nature of the 'meaninglessness' inherent in this condition. First, a point of clarification. The claim that 'without God, everything is meaningless' should be understood to refer to God in the same sense as in Nietzsche's claim in The Gay Science that 'God is dead'. 'God' is here used to refer not only to the idea of an omnipotent, omniscient, loving deity, or to the God of Abraham, Isaac, and Jacob, but to a unifying principle or logos governing the cosmos that gives the universe order, intelligibility, and meaning - a logos that provides the necessary 'proportion' between the human mind and the universe, the quest of the philosophers from even before Socrates. Living well requires understanding and accommodating oneself to this logos so that one's own life and life-activities fit into the larger patterns of the cosmos. Proper evaluation of the claim requires constantly holding this understanding in place. Pascal's claim is that the universe, considered in itself, does not bear this kind of proportion to the human mind. We are unable to work out our proper place in the cosmos, if indeed there is any cosmos, and not simply a chaos parallel to the chaos of our passions.

We can find the problem by beginning with a familiar Pascalian motif, the conflict between 'scepticism', or 'Pyrrhonism', and 'dogmatism'. These signify two different attitudes toward our as-if instinctive 'first principles', whether these are first principles of reason (such as that the whole is greater than the part or that nature abhors a vacuum) or of the heart (such as that happiness and life are to be sought or that happiness consists in the fulfilment of the passions). Reason, either theoretical or practical, is discursive and proceeds from premises to conclusions. ${ }^{9}$ As such it requires first principles from which to begin its process of calculation. The sceptic, or Pyrrhonist, demands that these first premises

${ }^{8}$ Leszek Kolakowski, God Owes Us Nothing (Chicago: University of Chicago Press, 1995), p. 133.

9 'The Art of Persuasion', pp. 194-195. 
themselves also be demonstrated by means of reason. That is, instead of allowing the calculative process of reason to begin, they continually regress upon their premises, and require demonstration of those. The only truths that survive this sceptical regress are those whose denials are self-contradictory; the rest are rejected or suspended.

The dogmatist, by way of contrast, insists upon accepting the first premises and allowing the calculative process to begin, insisting that 'we are not dreaming' (fr. 85) and the like. The dogmatist has the advantage that our nature is such as to require us to accept some principles and at least act as if they were true; the principles of 'nature' (whether true or false) win out in the field of life. We must act and we cannot avoid the power of these principles over our conduct; 'speaking in good faith and in all sincerity, we cannot doubt natural principles' (fr. 164). Likewise, we cannot avoid living as if life were meaningful.

But the Pyrrhonist retains the advantage of having undermined our confidence in our first premises. The continuous application of reason to our first premises or assumptions not only exposes uncertainty, it exposes arbitrariness and illusions, by making us aware of the groundlessness of our principles and the highly suspect mechanisms, self-deceptions, and all-too-convenient blind-spots that are involved in what we accept. The accidental character of our origin produces insuperable problems (fr. 164). It renders our beliefs and principles not only uncertain, but suspect, and as the method proceeds to find more and more instances of illusion, the suspicion becomes general. We discover that many of our beliefs and convictions of our hearts are due to custom; they vary from time to time and from place to place, and bear the mark of an accidental origin. How many others have this character? How much of what I believe and feel to be true is so only because of my own passions and my country's customs, or arbitrary facts about my origin? We must act, but can we act without a suspicion of ourselves?

We can begin at another point, the heart itself. Pascal's treatment of infinitude (fr. 229) is not meant to apply to astronomy and physics only. The upshot of his argument concerns a more general problem: how to determine a privileged starting point, a resting point - a single perspective among the infinite number of possible perspectives eligible for us to adopt - from which reason can begin. What shall we adopt as our first principles and regard as our truly 'natural desires'? These are the starting points from which reasoning or action can begin. The power of reason does not, in itself, allow us to pin down a starting point. 
A reason that could do this, Pascal says, would need to possess a power far exceeding ours; it would need to resemble God's omniscience, so as to contain the totality of knowledge at once. We, however, must make do with starting points that are, from the standpoint of reason, arbitrary and accidental. Since they stand at the beginning of our reasoning, they cannot be supported by it. The heart contains too many kinds of passions - those arising from the 'angel' and those arising from the 'brute', along with the variety of passions within these two groupings - so how can we determine which should be privileged? Given the complexity of the reasons found within the heart, and the conflict among these, 'follow your heart' is a counsel of despair whose folly is only exceeded by its impossibility. Since we must act, we will follow one set or another of principles, one conception of another of happiness, but the particular arrangement we favour cannot be grounded in reason, which only discerns an indefinite number of possible perspectives and approaches by which these principles might be organized.

Thus, the principles by which we live appear accidental and arbitrary in two senses: accidental in the sense that we cannot find a grounding for the principles we have, all too many of which appear suspect, and accidental in another sense, in that faced by the 'monstrousness' of human nature we inevitably privilege some one aspect of human nature or another without a clear justification for doing so. For Pascal the experience of our contingency is disorienting. Human knowledge and conduct lack foundations; we recognize of an indefinite number of other possible perspectives and possible understandings of human nature, along with any number of possible ways of life corresponding to these, but we lack the power to identify which of these is correct. Is the intuitive, commonsense perspective the appropriate one to begin with, or would it rather be better to adopt the kind of 'broader' and 'extremely alienated' 10 perspective that leads Tolstoy to describe human life as a 'temporal, incidental accumulation of particles' or a 'lump' whose 'fermentation' 'is called your life'? ${ }^{11}$ Should we follow the principle of utility or the categorical imperative? Is the correct perspective and starting point for ethics focused upon states of affairs, the formal character of action, the pattern of a person's life, or something else, the agent's character, the

${ }^{10}$ Meaning in Life (Oxford: Oxford University Press, 2013), pp. 130, 144.

${ }^{11}$ Leo Tolstoy, A Confession, trans. by Jane Kentish (New York: Penguin Books, 1987), pp. 39-40. 
qualities of care and empathy, the development and expression of power, etc.? Pascal's contention is that arguments over which perspective to adopt for evaluating human life will prove endless, as indeed all such discussion in analytic ethics have been; we feel certain that various moral judgments are correct, but we find no certainty once we begin the attempt to ground the judgment of the heart in the principles of reason.

We can now articulate the meaninglessness of life as considered in light of this experience of radical contingency. It is true that, for Pascal, human life's complex of ignorance, misery, and powerlessness could be described as meaningless, because any activities we undertake do nothing to significantly alter our condition. We are miserable and shall remain miserable, although we do at least have the power to distract ourselves through engagement with apparently purposive activities. In light of this life appears Sisyphean and meaningless.

Yet life as defined above can still be conceived of as a struggle in pursuit of a coherent set of goals, such as knowledge, happiness, and life, in which the striving can itself come to form a new form of meaning. For Pascal the interior dynamic of reason and the heart drives in another direction. Reason's sapping work, carried out against our first principles, exposes their lack of foundations, and the constant need nonetheless to live and act as if these principles were sure and true generates an interior conflict that undermines meaningfulness from within by undermining our confidence in all we devote ourselves to. Recognizing that whatever perspective we adopt to be accidental and arbitrary likewise alienates us from our lives and what we devote them to. When the destructive work of reason is finished we are left, finally, with a profound inarticulateness regarding our condition. For even the task of describing our state would require finding a perspective and set of principles and terms appropriate for human nature and our condition with which to articulate it, but it is these very things which we have been denied. Thus, meaninglessness resolves itself not into ceaseless, pointless reiteration, but, precisely insofar as human nature grows in self-consciousness and in the conscientious application of reason and devotion to truth, meaninglessness progresses into disorientation, self-alienation, and finally collapses into voiceless, despairing inarticulacy.

It is in this sense that we should say that Pascal held life to be meaningless without God. For just as Pascal held that only supernatural grace could cure the condition of ignorance, mortality, and misery (and overcome our wretchedness), so too he held we need an anchor outside 
ourselves to stabilize both reason and the heart. When Pascal is said to have favoured the 'reasons of the heart, which reason knows not' (fr. 680) this should be understood to apply to a specific set of reasons - not those we find in our corrupt state, which represent a mixture of custom, nature, and fantasy, but those arising from divine inspiration within the heart.

Considered in themselves, reasons provided inspired by divine inspiration are certainly reliable; they represent not an arbitrary, but an absolute, perspective. They are not compromised by our contingency or corruption, and they provide us with the point of view and the language necessary to understand and articulate our condition in all its monstrousness (fr. 681, 'The Art of Persuasion', 193-4). Thus divine reasons would cancel the destructive dynamic driving life toward meaninglessness. But if the reasons provided by divine inspiration are merely true, that will not privilege them in any way relative to the other principles that are undermined in humanity's interior conflict, such as the reasons that not only purport, but really are, grounded in nature. The reasons of inspiration do not possess a different epistemological status (for Pascal intends his conception of human reason to apply to any finite reason which does not grasp the totality of existence at once, fr. 230), but they are privileged. Being products of grace they arrive with power: grace transforms the heart by ordering it toward God and God's ways, i.e., by giving it delight in and desire for these things. ${ }^{12}$ Our interior conflict is in fact a war of the heart with itself: the calculations of reason, no less than the movement of the limbs, wait upon motives supplied by the heart before they are carried out.

The reasons of grace provide the perspective in which the monstrousness of human life - its doubled duality of mind and body, nature and corruption - is finally resolved in a single coherent point of view and the passion that strains against submission to God is quieted so that the recipient of grace is enabled to hold on to this perspective. We might summarize Pascal's answer thus: God is necessary for meaning because contact with an absolute perspective provides our contingent perspective with a fixed starting point, and divine grace is necessary for this perspective to be established in the heart and come to govern our nature. It is then evident that, according to Pascal, the reason that God is necessary for meaning is not that we need to orient our lives around

12 Blaise Pascal, 'Treatise Concerning Predestination', in Pensées and Other Writings, p. 223. 
a maximal value. God's capacity for curing our restlessness is tied to his capacity for bestowing grace, and not simply his standing as the highest good, fitting our capacity as dual beings who must be addressed not via the mind, the angel, alone, but via the heart, where the mind and body are united.

\section{PASCALIAN PESSIMISM}

Pascal's pessimism about reason (like his pessimism about other subjects) has had a long history of refutations and rebirths. It echoes in Diderot's Rameau's Nephew and in Rousseau's First and Second Discourses ${ }^{13}$ and resounds in the works of Kierkegaard and Dostoevsky, in Johannes Climacus's treatment of 'the dialectic of the beginning' in Kierkegaard's Concluding Unscientific Postscript ${ }^{14}$ and in Dostoevsky's portrayal of Ivan Karamazov's disintegrating personality in Brothers Karamazov. One also thinks of Camus' 'The Myth of Sisyphus' and Nietzsche's statement that from Pascal he learned 'an infinite amount.'. ${ }^{15}$ Each highlights a different aspect of the problem and reproduces it again in a different philosophical milieu. Each returns the reader again to face the conviction that there is no proportion between human nature or human reason and our world, and that an absolute commitment to reason yields alienation, not connection, because calculation turned upon itself in the form of reflection undermines itself.

The reason for focusing upon the problem of reason, rather than the problem of futility, is that if Pascal is right (or if any project in the nearby vicinity is correct), then we cannot settle the question of supernaturalism with the method of Meaning in Life and typical of much contemporary analytic ethics - the method of bringing theories to stand trial before intuitions. For the Pascalian, appealing to intuitions about meaning to answer the question of whether life can be meaningful must fail, for the erosion of our trust in such intuitions is the presupposition of the experience of meaninglessness. Appeals to intuition, instead of

${ }^{13}$ Cf. Peter Lawler, The Restless Mind (New York: Rowman \& Littlefield Publishers, 1993), and Mark Hulliung, 'Rousseau, Voltaire, and the Revenge of Pascal', in Cambridge Companion to Rousseau, pp. 57-77.

${ }^{14}$ Kierkegaard, Concluding Unscientific Postscript, A. Hannay (trans.) (Cambridge: Cambridge University Press, 2009), pp. 94ff.

${ }^{15}$ Nietzsche, Selected Letters of Friedrich Nietzsche, ed. and trans. by Christopher Middleton (Indianapolis: Hackett Publishing Company, 1996), p. 327. 
supporting the meaningfulness of life, then might appear to signify the opposite - the suspicion that, after all, we have no very good reasons for thinking it is so, that we must be dogmatic about this, that this is just another humiliation of 'proud reason'. Since the supernaturalist attack is levelled at the reliability of our 'natural' starting points, or intuitions, these cannot be defended by once more reiterating that unintuitive quality of the supernaturalist claim. Systematically anti-intuitive views are bound to be counter-intuitive.

We can see this if we consider how the 'incoherence argument' deployed against John Cottingham, for example, must fail to gain traction against Pascal. Metz argues that Cottingham's argument that life is meaningless in the absence of God fails because Cottingham affirms three propositions with the form: (1) I know 'If X, then Y' is true; (2) I know X obtains; (3) I do not know whether Y is true, where X is wrongness and $\mathrm{Y}$ is the existence of God. Metz makes the point that it is incoherent to claim to know that wrongness exists, and to claim to know that if wrongness exists then God exists, while denying knowing whether God exists. ${ }^{16}$ Yet if this argument were deployed against the Pascalian, what would the latter reply? 'Do I indeed know that anything is wrong?' The Pascalian will therefore diagnose the tendency to reaffirm (2) and deny (1) to the power of the heart. We reaffirm (2) because we are sure of it, but that certainty is not based in knowledge; rather, 'judgment goes with feeling' (fr. 671), and so this conviction is based in the heart, and in the impossibility of living without the conviction of wrongness. Once again, the duality of our nature produces confusion by tempting us to treat judgment and thought as equivalent to one another. Dostoevsky was a careful reader of Pascal, and Ivan Karamazov is in many respects a good Pascalian. Ivan's conclusions that without God, everything is permitted, but also meaningless, is a valid interpretation of Pascal's philosophy; the fact that Ivan could not in fact live in this way - that conscience will have its revenge even upon those who do not believe in it - does not refute his conclusion. For the power of conscience will make its claim without reason's support or even in opposition to its claims. By regarding our certainty concerning wrong as a matter of the heart, not of reason, the logical incoherence, if not the existential incoherence, is thereby removed.

${ }^{16}$ Meaning in Life, p. 88. 
For this reason, then, it does not seem to me that Metz's two projects entirely cohere. The great synthesis carried out in Parts I and III depends upon deploying a method that can't secure the project against the supernaturalist argument that without God, life is meaningless. Thus, the overall argument of the book appears incomplete. Part II of Meaning in Life aims to protect the synthesis from the supernaturalist critique as well as at adopting what can be salvaged from supernaturalist views, but it focuses on an overly narrow understanding of this argument and, by doing so, ignores or is forced to misconstrue how this argument has appeared in the works of its principal exponents. An effective defence against this sort of opponent would require Part II to carry out a very different kind of project. By engaging with the supernaturalist critique, Meaning in Life invites a response it is not well-fortified against.

Acknowledgements. I would like to express gratitude to Robert Audi, Joshua Seachris, and Roger Knights for their helpful advice in the writing of this paper. 